\title{
Oral Contraceptives and Breast Neoplasia: A Retrospective Study
}

\author{
MARTIN P. VESSEY, Sir RICHARD DOLL, PETER M. SUTTON
}

British Medical fournal, 1972, 3, 719-724

\section{Summary}

Between 1 December 1968 and 31 December 1971345 women aged 16-39 years with a lump in the breast (90 malignant and 255 benign) were interviewed at five London teaching hospitals together with 347 matched controls suffering from acute medical or surgical conditions or admitted to hospital for routine elective surgery. Questions were asked about each patient's medical, obstetric, menstrual, contraceptive, and social histories.

The data do not suggest that the use of oral contraceptives is related in any way to the risk of breast cancer but provide some evidence that the preparations may actually protect against benign breast disease. This protective effect is largely confined to women who continue to use oral contraceptives and have used them altogether for more than two years. Such women appear to have only about $25 \%$ as great a risk of being admitted to hospital for a breast biopsy as women who have never used oral contraceptives at all.

\section{Introduction}

In December 1968 we began a controlled study of the use of oral contraceptives by women admitted to hospital for primary treatment of breast cancer or for biopsy of a breast lump. In 1971 we reported some preliminary findings at the Second National Conference on Breast Cancer, Los Angeles, which related to the 436 patients ( 54 with breast cancer, 166 with benign breast disease, and 216 matched controls) who had been interviewed up to the end of 1970 (Vessey et al., 1971). We now present a more detailed analysis of this material to which we have

\footnotetext{
Department of the Regius Professor of Medicine, Radcliffe Infirmary, Oxford

MARTIN P. VESSEY, M.D., Lecturer in Epidemiology

Sir RICHARD DOLL, M.D., F.R.s., Regius Professor of Medicine

Department of Morbid Anatomy, University College Hospital Medical School, London W.C.1

PETER M. SUTTON, M.B., M.R.C.PATH., Reader in Morbid Anatomy
}

added data for the 256 patients ( 36 with breast cancer, 89 with benign breast disease, and 131 matched controls) who were interviewed during 1971 .

\section{Subjects and Method}

Permission to interview women with breast disease and other control patients was obtained from the medical staff committees at five London teaching hospitals (University College Hospital, the Royal Free Hospital, the Middlesex Hospital, Charing Cross Hospital, Guy's Hospital). At each of these hospitals arrangements were made for all women who (a) were aged 16-39 years, (b) had ever been married, and (c) were admitted to hospital for primary treatment of breast cancer or for biopsy of a breast lump to be notified.* These patients were then interviewed in hospital by one or other of two experienced medical social workers, and inquiries were made about the patient's medical, obstetric, menstrual, contraceptive, and social histories.

For each patient with breast cancer two controls were selected from among the women in the wards of the same hospital who were suffering from an acute medical or surgical condition or had been admitted to hospital for a routine elective operation. These control patients were chosen to match the patient with breast cancer in regard to age (within 5 years), having ever been married, and parity (within groups $0,1-2,3$ or more births) and were interviewed in the same way as the affected patient.

For each patient with benign breast disease one control was selected according to the same criteria and similarly interviewed. It should be noted that independence between the two control series was not required; thus the same control patient might be matched both with a patient with breast cancer and with a patient with a benign lesion.

At each hospital arrangements were made with the pathology departments to retain histological material for review by one of us (P.M.S.).

A total of 90 patients undergoing primary treatment for breast cancer and 255 undergoing biopsy for a breast lump that proved to be benign were interviewed at the five hospitals between 1 December 1968 and 31 December 1971. During the same period 347 controls were similarly interviewed, of whom 88

* Except at Guy's Hospital, where only patients with breast cancer were notified. 
were matched with patients in both of the study series. The diagnoses of the patients in the two control series are shown in Table I. About one-fifth had an acute medical condition, twofifths had an acute surgical condition, and the remainder had been admitted to hospital for routine elective surgery.

\section{Results}

\section{USE OF ORAL CONTRACEPTIVES}

The reference point chosen to assess the contraceptive histories of the women with breast disease was the time when the presence of a lump in the breast first became known to the affected patient, with corresponding times for the controls. For example, if a patient with a benign lesion had first noticed a breast lump six months before admission to hospital her contraceptive history was determined at that time, while the history of her matched control was determined at a time six months before the control patient was admitted to hospital. It should be noted, however, that $78 \%$ of the patients with breast cancer and $60 \%$ of the patients with benign breast disease were admitted to hospital within three months of the lump first being noticed, and that the results obtained using this procedure do not differ materially from those obtained when the reference point was taken to be the date of hospital admission.

The proportion of patients in each group who had been using an oral contraceptive during the month before the lump was first noticed (or during the corresponding month for the matched controls) together with the proportions who had used an oral contraceptive only before that time or had never used one at all are shown in Table II. The use of the preparations was less in both series of patients with breast disease than in the corresponding matched controls. The only important disparity, however, is that relating to the use of oral contraceptives during the month before the lump was first noticed in the benign breast disease group and in the corresponding period for the matched controls. This difference between the groups is highly significant statistically $(P=0.003$; Table III).

In Table IV the data are subdivided according to both the time when oral contraceptives were last used and the total duration of their use. Agreement between the data for the patients with breast disease, malignant and benign, and the matched controls is fairly close in all subclasses in Table IV except for one. In this subclass, which categorizes those patients who were using oral contraceptives during the month before the lump was first noticed and had been doing so altogether for more than 24 months, there are only $9(3.5 \%)$ of the patients with benign breast disease but $29(11.4 \%)$ of the matched controls. This single large difference is responsible for almost all of the disparity in the use of oral contraceptives between the patients with benign breast disease and their matched controls. In this subclass the mean durations of use were: benign breast disease 43.8 months, controls $45 \cdot 1$ months.

An analysis of the different types of oral contraceptive preparation used was made comparing (a) the patients with breast cancer and their matched controls, $(b)$ the nine patients with

TABLE I-Diagnoses of Control Patients

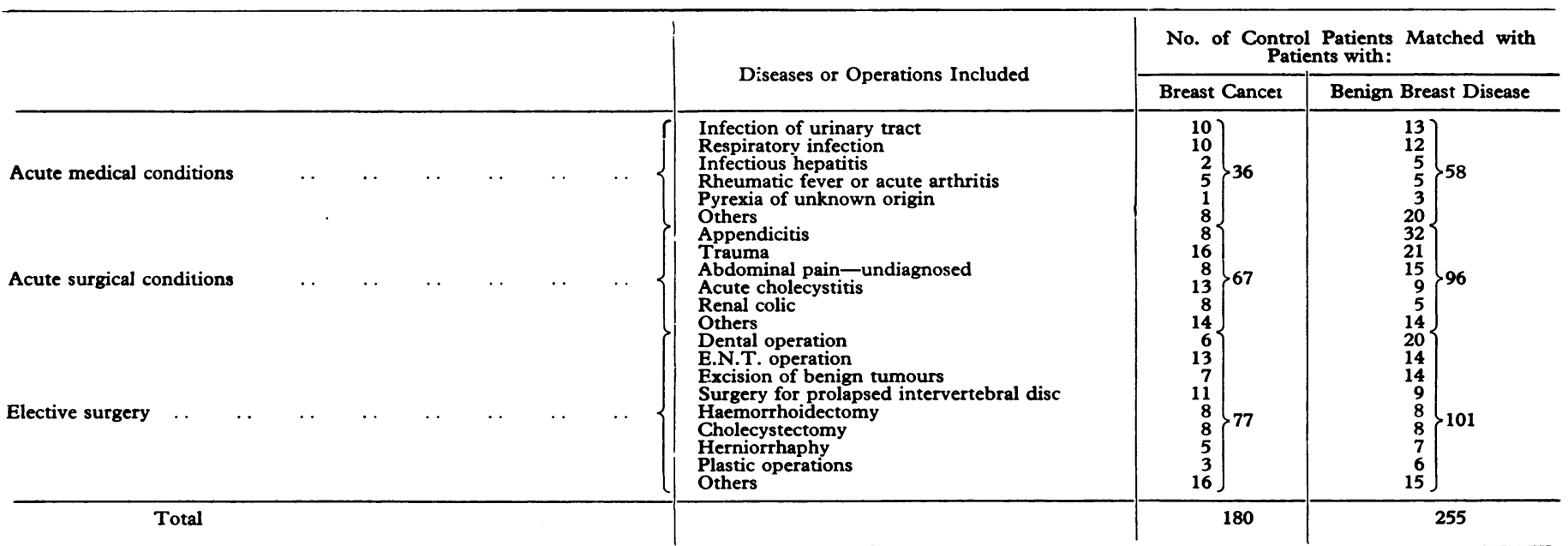

TABLE II-Use of Oral Contraceptives by Patients with Breast Cancer or Benign Breast Disease and their Matched Controls (Percentages in Parentheses)

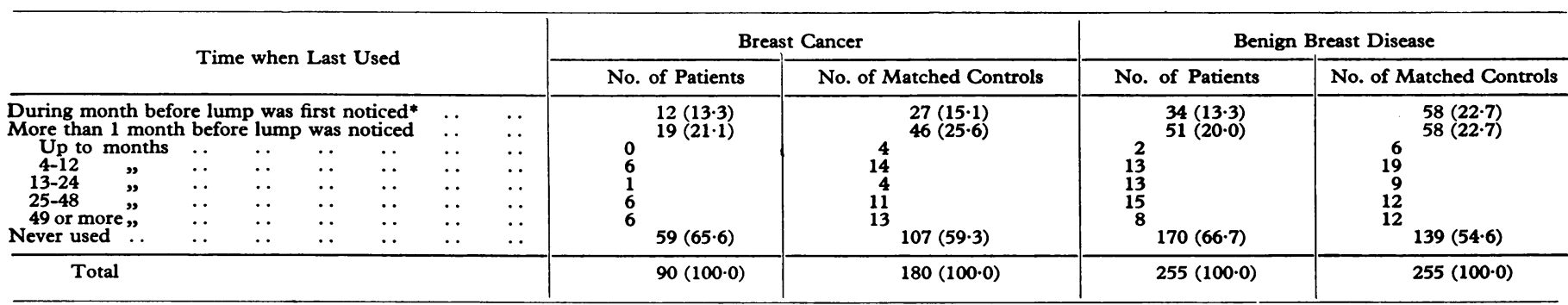

* For the matched controls this refers to the corresponding month, as defined in the text. 
benign breast disease who were "current users" of oral contraceptives with more than 24 months' total duration of use (hereafter referred to as "current long-term users of oral contraceptives") and the 29 corresponding controls, and (c) the remaining patients with benign breast disease and the remaining controls. No suggestive differences in the types of oral contraceptive used were found between the affected patients and the controls in any of these three comparisons.

\section{USE OF OTHER METHODS OF CONTRACEPTION}

Among those who had never taken oral contraceptives the use of other methods of birth control was reported more frequently by the patients with breast cancer or benign breast disease than by the controls, although none of the differences shown in the Table $\mathrm{V}$ reach statistical significance (the largest difference is that relating to the use of no method at all in the breast cancer group and in the corresponding controls; the value of $\chi_{1}{ }^{2}$ for this difference is $2 \cdot 1$ ). Clearly, however, there is no indication that the patients with breast disease had any less need for contraception than the control subjects.

\section{COMPARABILITY OF GROUPS}

The controls were selected in such a way as to ensure that they would be comparable with the patients with breast disease with respect to age, parity, whether ever married, and date and hospital of admission. They were also found to be comparable in regard to religion, country of birth, whether pregnant or in the puerperium, and whether postmenopausal. Differences were found, however, in the distribution of marital status-that is, whether currently married, widowed, divorced, or separatedsocial class, age at first pregnancy, and the frequency of a past history of breast biopsy (Table VI).

The patients with breast disease, malignant and benign, less frequently had broken marriages than their corresponding matched controls. This difference seems most likely to be an artefact resulting from the choice of hospital patients as controls (see Burns-Cox et al., 1969). Patients who are widowed, divorced, or separated (like single patients) tend to stay in hospital longer than patients who are living with their spouse and are, consequently, more readily available for interview. Additionally, however, the patients with breast disease were on average of higher social class than the matched controls. This

TABLE IV-Use of Oral Contraceptives by Patients with Breast Cancer or Benign Breast Disease and their Matched Controls classified by both Interval since last used and Total Duration of Use (Percentages in Parentheses)

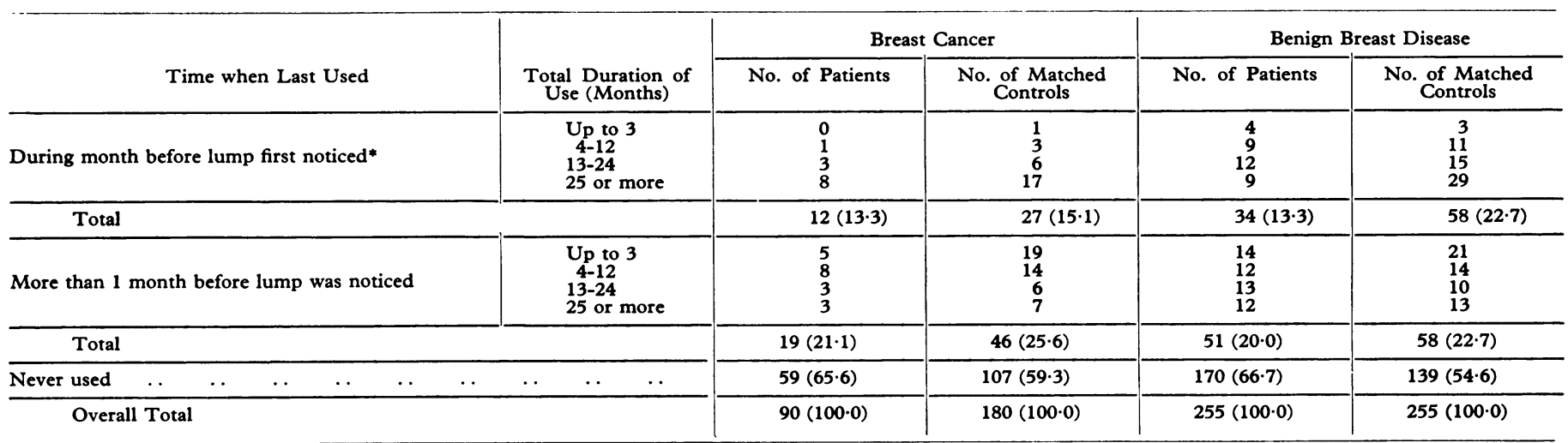

* For the matched controls this refers to the corresponding month, as defined in the text.

TABLE V-Use of Reversible Methods of Contraception by Patients with Breast Cancer or Benign Breast Disease and their Matched Controls. Data relate only to those Patients who had never used Oral Contraceptives (Percentages in Parentheses)

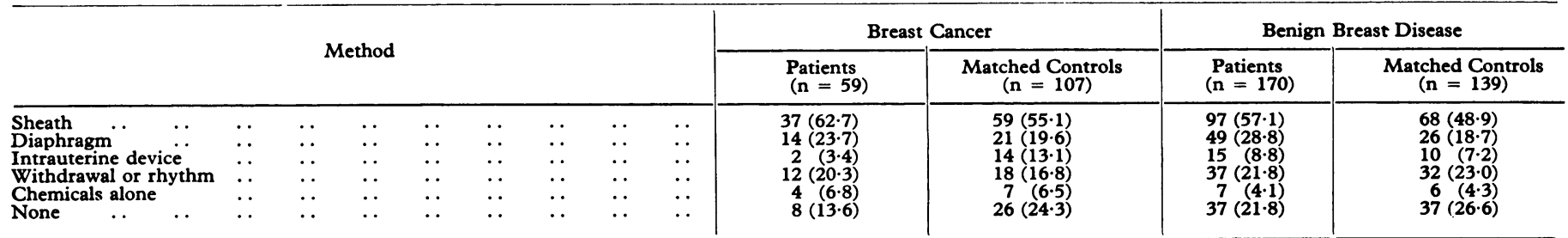

TABLE vI-Distribution of Patients with Breast Cancer or Benign Breast Disease and their Matched Controls according to Marital Status and Social Class, Age at First Pregnancy, and Presence or Absence of Past History of Breast Biopsy (Percentages in Parentheses)

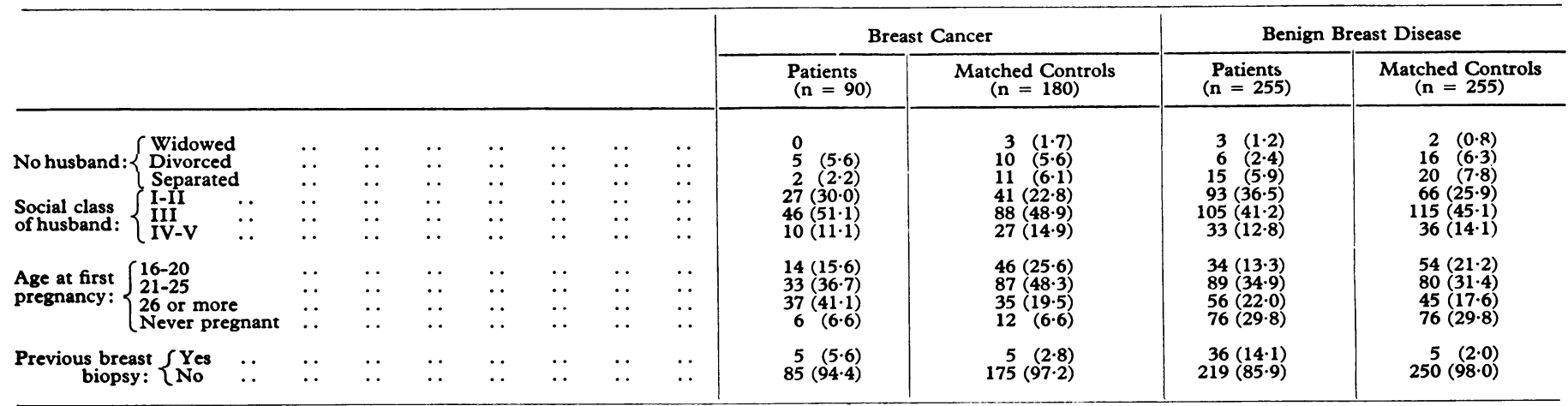


finding is consistent with other reports which have shown that breast cancer incidence and mortality appear to be positively correlated with socioeconomic status (Shapiro et al., 1968; Lowe and MacMahon, 1970; Zippin and Petrakis, 1971).

Pregnancy early in life has been shown to protect against the development of breast cancer (Valaoras et al., 1969; Lowe and MacMahon, 1970), and the data concerning age at first pregnancy, shown in Table VI, are consistent with the earlier findings. It is of considerable interest that the patients with benign breast disease, as well as those with cancer, tended to have their first pregnancy at an older age than the corresponding matched controls. The study design included matching for parity, which accounts for the absence of any differences between the patients with breast disease and the controls in the proportions who were never pregnant. Furthermore, matching for parity would be expected to reduce the differences between the affected patients and the controls with respect to age at first pregnancy.

Benign lesions of the breast tend to be recurrent, and the finding that $14 \%$ of the patients with benign breast disease had previously had a breast biopsy in comparison with only $2 \%$ of the controls was not unexpected.

In the present context the important point is whether these differences between the patients with breast disease and the controls could have biased the oral contraceptive comparisons to any major extent. This does not, in fact, appear to be the case. The use of oral contraceptives was marginally greater among the women with broken marriages and among the women in social classes I and II than among the remaining women, was not consistently associated with age at first pregnancy, and was slightly less frequent in those with a past history of breast biopsy than in those without such a history. Table VII shows the data standardized for each of these factors separately. It can be seen that the pattern of oral contraceptive use is hardly altered by this procedure. In particular, the marked deficiency of current long-term users of oral contraceptives in the benign breast disease group in comparison with the matched controls persists.

\section{HISTOPATHOLOGY OF EXCISED MATERIAL}

Histological review of the tissue excised from the patients with breast disease was undertaken by one of us (P.M.S.) without knowledge of the patients' contraceptive habits. The benign lesions were subdivided into five major categories-fibroadenoma, chronic cystic disease, simple lobular hyperplasia, other abnormalities, and normal tissue. The pattern of oral contraceptive use among the patients in these five categories, together with the corresponding data for the matched controls, is shown in Table VIII. In both the major histological categories (fibroadenoma and chronic cystic disease), together accounting for $80 \%$ of the benign breast lumps, there was a deficiency of current long-term users of oral contraceptives in comparison with the matched controls. No such difference was observed in the remaining $20 \%$ of cases with other conditions or no abnormality.

Three fibroadenomas with florid epithelial proliferation of the type described by Goldenberg et al. (1968) and by Brown (1970) as occurring in association with the use of oral contraceptives were found. Two of these lesions occurred in women who had never used oral contraceptives, while the third occurred in a woman who had used oral contraceptives for only one month almost two years before the presence of a lump in the breast was first discovered.

Histological review of material excised from the patients with breast cancer was unrewarding. About $85 \%$ of the tumours were of the classical scirrhous variety and no points of distinction were found between the lesions from patients who had used oral contraceptives and those from patients who had not.

\section{Discussion}

Hertz (1969) pointed out that if contraceptive steroids initiate malignant change in breast tissues de novo the consequences would probably not yet be detectable because human carcino-

TABLE VII-Use of Oral Contraceptives by Patients with Breast Cancer or Benign Breast Disease and their Matched Controls, standardized for Marital Status/Social Class, Age at First Pregnancy, and Past History of Breast Biopsy

\begin{tabular}{|c|c|c|c|c|c|c|}
\hline \multirow{2}{*}{\multicolumn{2}{|c|}{ Data Standardized for: }} & \multirow{2}{*}{ Use of Oral Contraceptives } & \multicolumn{2}{|c|}{ Breast Cancer } & \multicolumn{2}{|c|}{ Benign Breast Disease } \\
\hline & & & $\%$ Patients & $\%$ Matched Controls & $\%$ Patients & $\%$ Matched Controls \\
\hline Marital status/social class & .. & $\begin{array}{l}\text { Current*-up to } 24 \text { months } \\
\text { Current- }>24 \text { months } \\
\text { Past only } \\
\text { Never used }\end{array}$ & $\begin{array}{r}3 \cdot 9 \\
9 \cdot 4 \\
21 \cdot 2 \\
65 \cdot 5\end{array}$ & $\begin{array}{r}5.5 \\
9.7 \\
25 \cdot 3 \\
59.5\end{array}$ & $\begin{array}{r}9.8 \\
3.7 \\
19.9 \\
66 \cdot 6\end{array}$ & $\begin{array}{l}11 \cdot 2 \\
11 \cdot 8 \\
22 \cdot 8 \\
54 \cdot 2\end{array}$ \\
\hline Age at first pregnancy.. & $\cdot \cdot$ & $\begin{array}{l}\text { Current-up to } 24 \text { months } \\
\text { Current- }>24 \text { months } \\
\text { Past only } \\
\text { Never used }\end{array}$ & $\begin{array}{r}4 \cdot 8 \\
9 \cdot 4 \\
22 \cdot 6 \\
63 \cdot 2\end{array}$ & $\begin{array}{r}5 \cdot 6 \\
9 \cdot 2 \\
25 \cdot 7 \\
59 \cdot 5\end{array}$ & $\begin{array}{r}9 \cdot 6 \\
3 \cdot 4 \\
20 \cdot 8 \\
66 \cdot 2\end{array}$ & $\begin{array}{l}11 \cdot 5 \\
11 \cdot 1 \\
22 \cdot 7 \\
54 \cdot 7\end{array}$ \\
\hline Past history of breast biopsy & .. & $\begin{array}{l}\text { Current-up to } 24 \text { months } \\
\text { Current- }>24 \text { months } \\
\text { Past only } \\
\text { Never used }\end{array}$ & $\begin{array}{r}4 \cdot 5 \\
9 \cdot 0 \\
20 \cdot 8 \\
65 \cdot 7\end{array}$ & $\begin{array}{r}5 \cdot 5 \\
9 \cdot 3 \\
25 \cdot 3 \\
59 \cdot 9\end{array}$ & $\begin{array}{r}10 \cdot 3 \\
3 \cdot 6 \\
20 \cdot 2 \\
65 \cdot 9\end{array}$ & $\begin{array}{l}11 \cdot 9 \\
10 \cdot 7 \\
21 \cdot 3 \\
56 \cdot 1\end{array}$ \\
\hline None of these factors $\quad \ldots$ & .. & $\begin{array}{l}\text { Current-up to } 24 \text { months } \\
\text { Current- }>24 \text { months } \\
\text { Past only } \\
\text { Never used }\end{array}$ & $\begin{array}{r}4.4 \\
8.9 \\
21 \cdot 1 \\
65 \cdot 6\end{array}$ & $\begin{array}{r}5 \cdot 6 \\
9 \cdot 5 \\
25 \cdot 6 \\
59 \cdot 3\end{array}$ & $\begin{array}{r}9 \cdot 8 \\
3 \cdot 5 \\
20 \cdot 0 \\
66 \cdot 7\end{array}$ & $\begin{array}{l}11 \cdot 35 \\
11 \cdot 35 \\
22 \cdot 7 \\
54 \cdot 6\end{array}$ \\
\hline
\end{tabular}

* Current means in use during month before lump was first noticed or corresponding month, as defined in the text, for the matched controls.

Standard population for each contrast taken as the combined distribution for the patients with breast disease and the corresponding matched controls.

TABle vilI-Use of Oral Contraceptives by Patients with Different Types of Benign Breast Disease* and their Matched Controls

\begin{tabular}{|c|c|c|c|c|c|c|c|c|c|c|}
\hline \multirow{2}{*}{ Use of Oral Contraceptives } & \multicolumn{2}{|c|}{ Fibroadenomat } & \multicolumn{2}{|c|}{ Chronic Cystic Disease } & \multicolumn{2}{|c|}{ Simple Lobular Hyper- } & \multicolumn{2}{|c|}{ Other Abnormalities } & \multicolumn{2}{|c|}{ Normal Tissue } \\
\hline & $\begin{array}{c}\text { No. of } \\
\text { Patients }\end{array}$ & $\begin{array}{l}\text { No. of } \\
\text { Matched } \\
\text { Controls }\end{array}$ & $\begin{array}{l}\text { No. of } \\
\text { Patients }\end{array}$ & $\begin{array}{l}\text { No. of } \\
\text { Matched } \\
\text { Controls }\end{array}$ & $\begin{array}{l}\text { No. of } \\
\text { Patients }\end{array}$ & $\begin{array}{c}\text { No. of } \\
\text { Matched } \\
\text { Controls }\end{array}$ & $\begin{array}{l}\text { No. of } \\
\text { Patients }\end{array}$ & $\begin{array}{l}\text { No. of } \\
\text { Matched } \\
\text { Controls }\end{array}$ & $\begin{array}{l}\text { No. of } \\
\text { Patients }\end{array}$ & $\begin{array}{l}\text { No. of } \\
\text { Matched } \\
\text { Controls }\end{array}$ \\
\hline 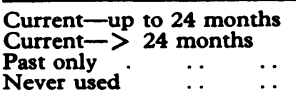 & $\begin{array}{r}8 \\
1 \\
17 \\
60\end{array}$ & $\begin{array}{l}13 \\
10 \\
20 \\
43\end{array}$ & $\begin{array}{r}9 \\
4 \\
26 \\
78\end{array}$ & $\begin{array}{r}8 \\
15 \\
27 \\
67\end{array}$ & $\begin{array}{r}2 \\
3 \\
3 \\
11\end{array}$ & $\begin{array}{r}3 \\
1 \\
2 \\
13\end{array}$ & $\begin{array}{r}4 \\
1 \\
3 \\
13\end{array}$ & $\begin{array}{r}1 \\
1 \\
7 \\
12\end{array}$ & $\begin{array}{l}2 \\
0 \\
2 \\
8\end{array}$ & $\begin{array}{l}4 \\
2 \\
2 \\
4\end{array}$ \\
\hline Total & 86 & 86 & 117 & 117 & 19 & 19 & 21 & 21 & 12 & 12 \\
\hline
\end{tabular}

* Twelve specimens could not be traced. The routine histological reports were used to allocate these patients to the appropriate category.

t Seven of these specimens showed multiple fibroadenomas. Of these, five related to patients who had never used oral contraceptives, one to a patient who had used oral contraceptives only in the past, and one to a patient who had been currently using oral contraceptives for a total duration of three months. 
TABLE IX-Persons first noticing a Lump in the Breast in Patients with Breast Cancer or Benign Breast Disease (Percentages in Parentheses)

\begin{tabular}{|c|c|c|c|c|c|c|}
\hline & \multirow{2}{*}{$\begin{array}{l}\text { Use of Oral } \\
\text { Contraceptives }\end{array}$} & \multicolumn{4}{|c|}{ Person Who First Noticed Lump } & \multirow{2}{*}{ Total } \\
\hline & & Patient or Husband & Family Doctor & $\begin{array}{l}\text { Family Planning } \\
\text { Doctor }\end{array}$ & Other Doctor & \\
\hline Breast Cancer & $\begin{array}{l}\text { Current } \\
\text { Past only } \\
\text { Never }\end{array}$ & $\begin{array}{l}12(100 \cdot 0) \\
19(100 \cdot 0) \\
56(94.9)\end{array}$ & $\begin{array}{l}0 \\
0 \\
0\end{array}$ & $\begin{array}{ll}0 & \\
0 & \\
1 & (1 \cdot 7)\end{array}$ & $\begin{array}{ll}0 & \\
0 & \\
2 & (3.4) \\
\end{array}$ & $\begin{array}{l}12(100 \cdot 0) \\
19(100 \cdot 0) \\
59(100 \cdot 0)\end{array}$ \\
\hline Total & & $87(96 \cdot 7)$ & 0 & $1 \quad(1 \cdot 1)$ & $2 \quad(2 \cdot 2)$ & $90(100 \cdot 0)$ \\
\hline Benign Breast Disease & $\begin{array}{l}\text { Current } \\
\text { Past only } \\
\text { Never }\end{array}$ & $\begin{aligned} 29 & (85 \cdot 3) \\
42 & (82 \cdot 3) \\
148 & (87 \cdot 1)\end{aligned}$ & $\begin{array}{ll}1 & (2.9) \\
2 & (3.9) \\
8 & (4.7) \\
\end{array}$ & $\begin{array}{ll}2 & (5.9) \\
1 & (2.0) \\
1 & (0.6) \\
\end{array}$ & $\begin{array}{rr}2 & (5.9) \\
6 & (11.8) \\
13 & (7.6) \\
\end{array}$ & $\begin{array}{r}34(100 \cdot 0) \\
51(100 \cdot 0) \\
170(100 \cdot 0) \\
\end{array}$ \\
\hline Total & & $219 \quad(85 \cdot 9)$ & $11 \quad(4 \cdot 3)$ & $4 \quad(1 \cdot 6)$ & $21 \quad(8 \cdot 2)$ & $255(100 \cdot 0)$ \\
\hline
\end{tabular}

gens seldom produce an overt effect in less than 10 years. If, however, oral contraceptives alter the rate of growth of latent tumours or affect the rate of change from a premalignant state to malignancy an effect might be seen earlier. Accordingly, we thought it worth while to start this investigation in late 1968 when oral contraceptives had been in use for seven years. We propose, however, to continue to collect new data for several more years in case an effect becomes apparent only after longer use.

The present findings are reassuring. There is no suggestion that the use of oral contraceptives is related in any way to the risk of breast cancer in women under the age of 40 , while there is some evidence that their use may actually protect against benign breast disease in this age group, as was originally suggested by Pincus and his colleagues (see Garcia et al., 1965). Our data indicate that this protective effect is largely confined to women who continue to use oral contraceptives and have used them altogether for more than two years. Such women appear to have only about $25 \%$ as great a risk of being admitted to hospital for a breast biopsy as women who have not used oral contraceptives at all. The protective effect seems to apply both to fibroadenoma and to chronic cystic disease of the breast and is not obviously related to any particular type of oral contraceptive. A far larger body of data would be required, however, for the latter statement to be made with confidence. These benign lesions vary in severity during the menstrual cycle, and since oral contraceptives suppress the natural fluctuation of endogenous hormones during the menstrual cycle some effect on the occurrence of benign breast disease might be expected.

When the study was planned it was thought that both women using oral contraceptives and their doctors might be especially alert for the appearance of breast lumps and that this might lead to a serious bias. Such a bias would, of course, tend to produce a spurious positive association between the use of oral contraceptives and breast disease. The data in Table IX provide some evidence that there was no special tendency for doctors to notice lumps in the breast more often in women using oral contraceptives than in other women. Table IX also shows that while $97 \%$ of the breast cancers were first noticed by the woman herself or by her

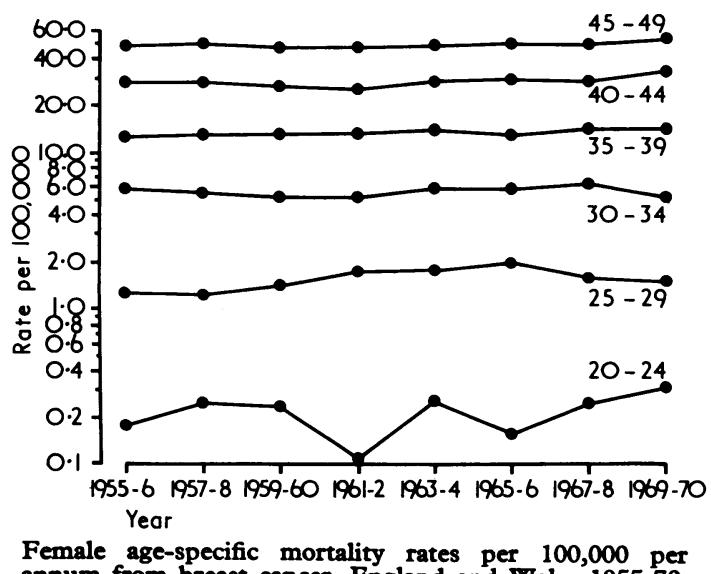

Female age-specific mortality rates per 100,000 per
annum from breast cancer. England and Wales $1955-70$. husband the corresponding figure for the benign lesions was only $86 \%$. Perhaps, since malignant lumps generally increase in size more rapidly than benign ones, they are more likely to command the patients' attention.

Speculation on the possible relation between oral contraceptives and breast cancer has been mostly based on knowledge of the epidemiology of the disease and on animal experiments (Allen, 1969; Hertz, 1969; Doll, 1970; Leis, 1970). Little direct human evidence has been published, but mortality trends for breast cancer in England and Wales are reassuring (see Chart), as are corresponding data in the United States (Vessey, 1970). Incidence rates for breast cancer from the Connecticut and California cancer registries have been examined in detail by Arthes et al. (1971), who found that there had been increases in the incidence of the disease at certain ages in both sets of data but concluded that it was difficult to ascribe the increases to any particular factor.

Arthes et al. (1971) have also reported some preliminary findings in a case-control study in progress at the Johns Hopkins Hospital, Baltimore. Their study concerns women aged 15-75 years, since they are interested not only in oral contraceptives but also in postmenopausal replacement therapy with oestrogens. Of the first 119 patients with breast cancer 29 had at some time used female sex hormones, while the number expected from the experience of 295 controls was 37; for the first 135 patients with benign breast lesions the corresponding observed and expected numbers were 47 and 41 respectively. The latter finding, it will be noted, is not in keeping with our results, but a proper assessment will have to await the publication of more detailed information by Arthes and his colleagues.

Several studies have compared the histopathological features of breast lesions excised from women using oral contraceptives with those from other women. Fechner (1970a, 1970b, 1970c) examined 54 fibroadenomas, 25 specimens of tissue classified as chronic cystic disease, and five breast cancers removed from women receiving oral contraceptives; he found no distinctive features which he could relate to use of the steroids. As mentioned above, however, Goldenberg et al. (1968) and Brown (1970) reported on four patients and one patient respectively who were using oral contraceptives and who were treated for fibroadenomas showing a bizarre type of epithelial proliferation thought possibly to be related to the use of the preparations. Our experience has been in line with that of Fechner; we have found it impossible to distinguish lesions, benign or malignant, excised from the breasts of women using oral contraceptives from those excised from the breasts of women not doing so.

It is likely to be many years before the question of the possible relation between oral contraceptives and breast cancer is finally settled, but the available data are reassuring. In addition to this study and the investigation at the Johns Hopkins Hospital, retrospective studies are in progress at the Yale University School of Medicine and the University of California School of Public Health. In the United Kingdom large scale prospective studies are being undertaken by the Royal College of General Practitioners (see Kay, 1970) and by the Regius Department of Medicine at Oxford in conjunction with the Family Planning Association (see Vessey, 1971). 
We wish to thank the medical staff at University College Hospital, the Royal Free Hospital, the Middlesex Hospital Charing Cross Hospital, and Guy's Hospital for allowing us to study patients under their care, and Miss Keena Jones and Mrs. Eva Goldenberg for conducting the interviews. We are grateful also to the Medical Research Council, under whose auspices this work was begun when two of us (M.P.V. and R.D.) were members of the Council's Statistical Research Unit, and which continues to employ Miss Jones and Mrs. Goldenberg.

\section{References}

Allen, W. (1969). Cancer (Philadelphia), 24, 1137.

Arthes, F. G., Sartwell, P. E., and Lewison, E. F. (1971). Cancer (Philadelphia), 28, 1391.

Brown, J. M. (1970). Medical Fournal of Australia, 1, 276.

Burns-Cox, C. J., Doll, R., and Ball, K. P. (1969). British Heart fournal, 31, 485.

Doll, R. (1970). Fournal of Biosocial Science, 2, 367.
Fechner, R. E. (1970a). American fournal of Clinical Pathology, 53, 857.

Fechner, R. E. (1970b). Cancer (Philadelphia), 25, 1332.

Fechner, R. E. (1970c). Cancer (Philadelphia), 26, 1204.

Garcia, C. R., Pincus, G., Rocamora, H., and Wallach, E. E. (1965). In Proceedings of the VI Pan-American Congress of Endocrinology, p. 138. Amsterdam, Excerpta Medica.

Goldenberg, V. E., Wiegenstein, L., and Mottet, N. K. (1968). American Fournal of Clinical Pathology, 49, 52.

Hertz, R. (1969). Cancer (Philadelphia), 24, 1140.

Kay, C. R. (1970). Fournal of the Royal College of General Practitioners, 19,

Leis, H. P. (1970). New York State fournal of Medicine, 70, 2911.

Lowe, C. R., and MacMahon, B. (1970). Lancet, 1, 153.

, M. C., and Morrow, R. H. (1970). British fournal of Preventive and Social Medicine, 24, 42.

Shapiro, S., Strax, P., Venet, L., and Fink, R. (1968). American fournal of Public Health, 58, 820

Valaoras, V. G., MacMahon, B., Trichopoulos, D., and Polychronopoulou, A. (1969). International fournal of Cancer, 4, 350 .

Vessey, M. P. (1970). M.D. thesis, University of London

Vessey, M. P. (1971). American fournal of Epidemiology, 94, 202.

Vessey, M. P., Doll, R., and Sutton, P. M. (1971). Cancer (Philadelphia), 28, 1395.

Zippin, C., and Petrakis, N. L. (1971). Cancer (Philadelphia), 28, 1381.

\title{
Daily Requirement of Oxygen to Reverse Pulmonary Hypertension in Patients with Chronic Bronchitis
}

\author{
R. D. STARK, P. FINNEGAN, J. M. BISHOP
}

British Medical fournal, 1972, 3, 724-728

\section{Summary}

We have shown previously in patients with chronic bronchitis that correction of the hypoxaemia by continuous administration of oxygen substantially reduced the pulmonary hypertension by reversal of structural changes in the pulmonary resistance vessels. We have now demonstrated that such improvements may occur with less than continuous oxygen. Treatment with oxygen for 18 hours daily significantly decreased pulmonary arterial pressure and pulmonary vascular resistance. Oxygen therapy for 15 hours a day also decreased pulmonary vascular resistance; such a regimen is practicable in the home, is consistent with a working day free from the constraints of an oxygen supply, and should reduce the number of episodes of congestive cardiac failure.

\section{Introduction}

Patients who are chronically hypoxaemic because of chronic bronchitis frequently develop pulmonary hypertension. This leads to right ventricular hypertrophy and right ventricular failure. In these patients the cardiac failure becomes a major part of their disability, and its presence carries a particularly. poor prognosis. Of a large series of patients with chronic bronchitis studied by Renzetti, McClement, and Litt (1966) $53 \%$ died within four years. Those in the group who had a history of congestive cardiac failure suffered a mortality of $73 \%$ in the same period. Ude and Howard (1971) found that $68 \%$ of patients with chronic bronchitis who had survived their first episode of congestive cardiac failure died within the next five years. A similar figure was reported at the same centre 14 years earlier by Stuart-Harris and Hanley (1957). Since antibiotics and powerful diuretics have failed to improve the prognosis a

Department of Medicine, University of Birmingham, Queen Elizabeth Hospital, Birmingham 15

R. D. STARK, M.B., PH.D., Research Fellow

P. FINNEGAN, M.B., M.R.C.P., Lecturer in Medicine

J. M. BISHOP, M.D., P.R.C.P., Professor of Medicine more promising approach may be to attempt to prevent congestive cardiac failure by reduction of the pulmonary hypertension; the analogy with systemic hypertension is obvious.

The structural basis for the pulmonary hypertension has been shown by Hicken, Heath, Brewer, and Whitaker (1965) and Hasleton, Heath, and Brewer (1968) to be a pattern of changes in the pulmonary arterioles and small pulmonary arteries unique to conditions associated with chronic hypoxaemia. The media of the arterioles is thickened by the deposition of circular smooth muscle, and longitudinal bundles of muscle appear in the intima of the arterioles and small arteries.

In 1968 Abraham, Cole, and Bishop reported on six hypoxaemic patients in the late phase of chronic bronchitis in whom episodes of right heart failure had occurred. Right heart catheterization confirmed that pulmonary hypertension was present. The hypoxaemia was then corrected for periods of four to eight weeks by continuous administration of oxygen in an inspired concentration of about $30 \%$. Pulmonary arterial pressure and pulmonary vascular resistance decreased significantly. Similar responses to continuous oxygen were reported by Levine et al. (1967).

The measurements of pulmonary arterial pressure were made after the patients had been breathing air for two hours. Thus the decrease in pulmonary arterial pressure was not an acute response dependent on a raised oxygen tension but was an effect lasting many hours. When the oxygen therapy was finally discontinued there was a gradual rise in pulmonary arterial pressure over a period of weeks (Abraham et al., 1968). These responses would be consistent with the following explanation.

Hypoxaemia due to chronic bronchitis leads to a structural change in the pulmonary arterioles and small arteries, and this change maintains the pulmonary hypertension. Correction of the hypoxaemia by continuous oxygen therapy leads to regression of the structural change in the pulmonary vessels and reversal of the pulmonary hypertension. Histological study of the pulmonary vessels before and after oxygen treatment is not possible in man but studies on rats have shown that similar structural changes occurred in the small pulmonary arteries while the rats were in a hypoxic environment (Abraham, Kay, Cole, and Pincock, 1971). These changes reversed when the oxygen tension was returned to normal. 